Rapid Reviews COVID-19

\title{
Reviews: "Age-Specific Mortality and Immunity Patterns of SARS-CoV-2 Infection in 45 Countries"
}

\author{
Vana Sypsa ${ }^{1}$ \\ ${ }^{1}$ University of Athens
}

Published on: Mar 03, 2022

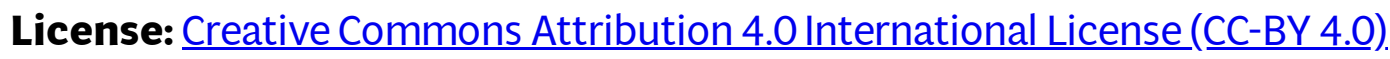


To read the original manuscript, click the link above.

Reviewer 1 (Vana S...) | |

RR:C19 Strength of Evidence Scale Key.

$$
\begin{aligned}
& \text { प्रमप् = Misleading } \\
& \text { प्र प्र० = Not Informative }
\end{aligned}
$$

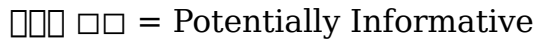

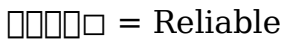

$$
\begin{aligned}
& \text { प्राप्र }=\text { Strong }
\end{aligned}
$$

To read the reviews, click the links below. 